\title{
Selective substitution of long-acyl groups into alcohols of kraft lignin over transesterification using ionic liquid
}

\author{
Shiori Suzuki and Tadahisa Iwata ${ }^{*}$ []
}

\begin{abstract}
Kraft lignin is a valuable aromatic renewable resource that is discharged in large quantities during the kraft pulping process. In this study, kraft lignin derivatives with improved solubility and thermal properties were prepared by a facile chemical modification of the aliphatic hydroxy $(\mathrm{R}-\mathrm{OH})$ group in kraft lignin with various ester groups. Kraft lignin was subjected to homogeneous transesterification with vinyl esters as acyl donors using an ionic liquid as a green solvent and catalyst. The selective introduction of acyl groups into the R-OH group was confirmed by nuclear magnetic resonance (NMR) spectroscopy, and it was estimated that approximately $90 \%$ of the $\mathrm{R}-\mathrm{OH}$ group was converted whereas more than $80 \%$ of the aromatic hydroxy $(\mathrm{Ar}-\mathrm{OH})$ group was retained. The $\mathrm{R}-\mathrm{OH}$-selective introduction of long-chain acyl groups of more than six carbons successfully provided superior solubility in common low-boiling solvents, such as chloroform and tetrahydrofuran, and sufficient heat-meltability to be molded into films by hot-pressing. All the kraft lignin derivatives showed high glass transition temperatures of over $100^{\circ} \mathrm{C}$, indicating their potential to be heat-resistant materials. The kraft lignin derivatives, in which only the $\mathrm{R}-\mathrm{OH}$ group was acylated, retain their inherently rich Ar-OH groups and thus, can be applied as desirable precursors in a wide range of further chemical treatments for functional polymer materials.
\end{abstract}

Keywords: Lignin, Hydroxy groups, Transesterification, lonic liquid

\section{Introduction}

Kraft lignin is an industrial lignin obtained from the byproduct (i.e., black liquor) of the kraft pulping process, which accounts for approximately $85 \%$ of the total lignin production in the world [1]. Currently, the annual production of kraft lignin is approximately 630,000 tons. However, it is mainly used in the form of combustion for heat recovery, resulting in low-value utilization. Although high-value utilization of kraft lignin is in demand, there has been no significant progress in industrialization. The major factors that prevent its effective utilization, such as polymeric materials, are: (1) low molecular weight

\footnotetext{
*Correspondence: atiwata@g.ecc.u-tokyo.ac.jp Laboratory of Science of Polymeric Materials, Department of Biomaterial Sciences, Graduate School of Agricultural and Life Sciences, The University of Tokyo, 1-1-1 Yayoi, Bunkyo-ku, Tokyo 113-8657, Japan
}

due to considerable decomposition during alkaline cooking; (2) hard and brittle nature related to the high glass transition temperature $\left(T_{\mathrm{g}}\right)$, and (3) poor processability based on the insolubility in common solvents and lack of heat-meltability.

Despite the difficulties in material application, kraft lignin has an attractive character as an inherently multifunctional polymer having not only aliphatic hydroxy $(\mathrm{R}-\mathrm{OH})$ and carboxy $(\mathrm{COOH})$ groups, but 5-10 times more abundant aromatic hydroxy (Ar-OH) groups than native lignin. Notably, the Ar-OH group is a valuable functional group, because it is more chemically reactive than the $\mathrm{R}-\mathrm{OH}$ group and can easily serve as a reaction point for thermosetting and chemical crosslinking of kraft lignin. Furthermore, the $\mathrm{Ar}-\mathrm{OH}$ group is known to have antioxidant ability [2, 3] and adsorption capability for metals $[4,5]$. We hypothesized that 
if the poor processability of kraft lignin was improved by a certain modification method while retaining the rich $\mathrm{Ar}-\mathrm{OH}$ group, the resultant kraft lignin derivative would be a valuable precursor for polymeric materials with the unique functions in addition to the inherent high thermal stability of aromatic polymers.

Esterification of the hydroxy $(\mathrm{OH})$ groups in kraft lignin is one of the simplest and oldest chemical modification methods for improving its physicochemical properties [6-8]. Although acyl halides and anhydrides are typically used as highly activated acyl donors in the presence of catalysts, it has been reported that there is little chemoselectivity for $\mathrm{R}-\mathrm{OH}$ and $\mathrm{Ar}-\mathrm{OH}$ groups. We focused on the use of ionic liquids (ILs) to develop an efficient and sustainable functionalization process for kraft lignin.

ILs are molten organic salts with melting points below $100{ }^{\circ} \mathrm{C}$ [9] and can be a platform for biomass conversion in a wide range of applications $[10,11]$. 1-Ethyl-3-methylimidazolium acetate (EmimOAc) is an excellent solvent for biopolymers such as cellulose [12] and lignin [13], and functions as an organocatalyst for the transesterification of $\mathrm{R}-\mathrm{OH}$ and $\mathrm{Ar}-\mathrm{OH}$ groups with relatively stable vinyl esters as acyl donors [14, 15]. Moreover, in situ ${ }^{1} \mathrm{H}$ nuclear magnetic resonance (NMR) spectroscopy of the transesterification between low-molecular-weight model compounds with $\mathrm{R}-\mathrm{OH}$ and $\mathrm{Ar}-\mathrm{OH}$ groups and isopropenyl acetate (IPAc) revealed that EmimOAc promotes not only acetylation of both $\mathrm{OH}$ groups but also selective deacetylation of the instantaneously formed aromatic acetyl (Ar-OAc) group [16, 17]. Consequently, it was demonstrated that only R-OH group in kraft lignin was acetylated in one-pot two-step reaction using EmimOAc, IPAc, and a tiny amount of water as a proton source for selective deacetylation of the Ar-OAc group [18].

The advantage of esterification is that it provides wide and desirable material properties by tuning the degrees of substitution and chemical structures of the introduced ester groups (e.g., alkyl chain lengths). The purpose of this study was to develop functional kraft lignin derivatives with excellent solubility, heat-meltability, and thermal stability, via simple and sustainable conversion process. First, the applicability of the $\mathrm{R}-\mathrm{OH}$-selective modification system using EmimOAc was verified using various types of vinyl esters with different alkyl chain lengths as acyl donors. Hereafter, the solubility in common solvents, thermal stability, and hot-press moldability of the obtained kraft lignin derivatives were investigated to clarify the correlation between the alkyl chain length of the ester groups, which was selectively introduced into the $\mathrm{R}-\mathrm{OH}$ group in kraft lignin, and the resultant physicochemical properties.

\section{Materials and methods \\ Materials}

EmimOAc was purchased from Nippon Nyukazai Co., Ltd. (Tokyo, Japan) and used without further purification. Anhydrous dimethyl sulfoxide (DMSO) was obtained from Sigma-Aldrich Co., LLC. (St. Louis, MO, USA). Vinyl esters were purchased from Tokyo Chemical Industry Co., Ltd. (Tokyo, Japan) and used as received. Kraft lignin ([R-OH]: $2.7 \mathrm{mmol} \mathrm{g}^{-1}$, [Ar-OH]: $3.4 \mathrm{mmol} \mathrm{g}^{-1}$ ) was procured from Sigma-Aldrich Co., LLC. (St. Louis, MO, USA) and dried under vacuum at $70{ }^{\circ} \mathrm{C}$ until a constant weight before use. Other chemicals were commercially available and used as received unless otherwise stated.

\section{Selective $\mathrm{R}-\mathrm{OH}$ modification in kraft lignin}

Kraft lignin (0.60 g, $6 \mathrm{wt} \% /$ EmimOAc]) in EmimOAc $(10 \mathrm{~g})$ was dried under vacuum at $80{ }^{\circ} \mathrm{C}$ for $2 \mathrm{~h}$ to remove moisture. After DMSO $(15 \mathrm{~mL})$ was added to the solution under a $\mathrm{N}_{2}$ atmosphere, the resultant mixture was stirred at $80{ }^{\circ} \mathrm{C}$ for $2 \mathrm{~h}$ to completely dissolve the kraft lignin. As an acyl donor, 2 eq./[R-OH] of vinyl esters with different carbon numbers from 2 to 8 (Table 1) were added to the reactant solution using a micro-syringe. The resultant solution was further stirred for $2 \mathrm{~h}$ at $80{ }^{\circ} \mathrm{C}$ to perform the esterification of both $\mathrm{R}-\mathrm{OH}$ and $\mathrm{Ar}-\mathrm{OH}$ groups of kraft lignin and selective de-esterification of the generated aromatic ester (Ar-OR) groups (Scheme 1). The reacted solution was poured into $600 \mathrm{~mL}$ of distilled water to precipitate the light brown particles. After centrifugation $\left(4^{\circ} \mathrm{C}, 1 \mathrm{~h}\right.$, $18,000 \mathrm{rpm})$, the precipitated polymer was collected by

Table 1 Experimental conditions and yields of the kraft lignin derivatives

\begin{tabular}{|c|c|c|c|c|c|}
\hline \multirow[t]{2}{*}{ Entry } & \multirow[t]{2}{*}{ Kraft lignin (g) } & \multicolumn{3}{|l|}{ Acyl donor } & \multirow[t]{2}{*}{ Yield (g) } \\
\hline & & Reagent & $\begin{array}{l}\text { Carbon } \\
\text { number }\end{array}$ & $\overline{m^{a}}$ & \\
\hline 1 & 0.60 & Vinyl acetate (VAC) & 2 & 0.27 & 0.57 \\
\hline 2 & 0.60 & $\begin{array}{l}\text { Vinyl propionate } \\
\text { (VPr) }\end{array}$ & 3 & 0.32 & 0.57 \\
\hline 3 & 0.60 & Vinyl butyrate (VBu) & 4 & 0.37 & 0.61 \\
\hline 4 & 0.60 & $\begin{array}{l}\text { Vinyl hexanoate } \\
\text { (VHe) }\end{array}$ & 6 & 0.46 & 0.66 \\
\hline 5 & 0.60 & $\begin{array}{l}\text { Vinyl octanoate } \\
\text { (VOc) }\end{array}$ & 8 & 0.57 & 0.72 \\
\hline
\end{tabular}

${ }^{\text {a }}$ Calculated as 2 eq./[R-OH] of kraft lignin 


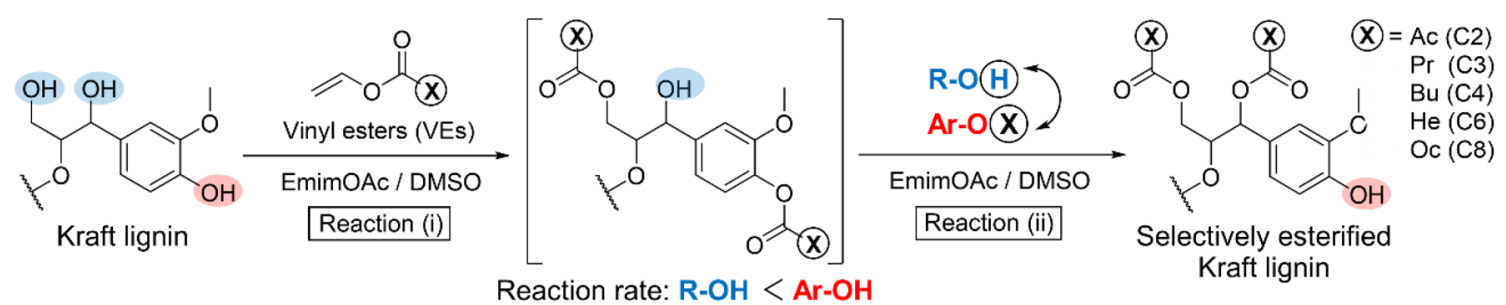

Scheme 1 Targeted strategy for R-OH selective esterification of kraft lignin using an EmimOAc catalyst

vacuum filtration and repeatedly washed with distilled water. After freeze-drying for 2 days, it was vacuum dried at $70{ }^{\circ} \mathrm{C}$ for over $24 \mathrm{~h}$ to yield the esterified kraft lignin.

\section{Nuclear magnetic resonance (NMR) spectroscopy}

The ${ }^{1} \mathrm{H},{ }^{13} \mathrm{C}$, and ${ }^{31} \mathrm{P}$ NMR spectra in solution were recorded using a JNM-ECA 600 spectrometer (JEOL Ltd., Tokyo, Japan) in deuterated solvents. All NMR spectra were analyzed using a Delta NMR software (JEOL Ltd., Tokyo, Japan), and the chemical shifts $(\delta, \mathrm{ppm})$ were referenced to tetramethylsilane (TMS, $\delta=0 \mathrm{ppm}$ ) as an internal standard.

The contents of $\mathrm{OH}$ groups in kraft lignin and the ester derivatives were estimated by quantitative ${ }^{31} \mathrm{P}$ NMR analysis via phosphitylation of the samples, according to previous studies $[19,20]$. First, the phosphitylation of kraft lignin and ester derivatives was conducted using the common phosphitylation reagent, 2-chloro-4,4,5,5-tetramethyl-1,3,2-dioxaphospholane (TMDP), at room temperature $\left(25^{\circ} \mathrm{C}\right)$ for $15 \mathrm{~min}$ in the same manner as in our previous reports [16-18]. The used NMR spectrometer was the same JNM-ECA 600 spectrometer, and two kinds of internal standards of (1) $N$-hydroxy-5-norbornene2,3-dicarboxylic acid imide and (2) cyclohexanol (10 g $\mathrm{L}^{-1}$, each) were applied with a relaxation reagent of tris(2,4-pentanedionato)-chromium(III) $\left(5 \mathrm{~g} \mathrm{~L}^{-1}\right)$ in chloroform- $d_{1} /$ pyridine mixed solvent. The inverse-gated ${ }^{1} \mathrm{H}$ decoupling sequence was employed with a recycle delay of $25 \mathrm{~s}$. The free induction decays of 128 were collected and averaged to obtain the ${ }^{31} \mathrm{P}$ NMR spectra.

\section{Size exclusion chromatography (SEC)}

The molecular weights distributions of kraft lignin and the ester derivatives were determined by SEC (UFLC system, Shimadzu Co., Kyoto, Japan) based on polystyrene standards. All SEC measurements were carried out at $40{ }^{\circ} \mathrm{C}$ using TSK gel $\alpha-\mathrm{M}$ (Tosoh Co., Tokyo, Japan), and $0.01 \mathrm{~mol} \mathrm{~L}^{-1} \mathrm{LiBr}$ in dimethylformamide (DMF, HPLC grade, Kanto Chemicals Co., Inc., Tokyo, Japan), which was used as the eluent at a flow rate of $1.0 \mathrm{~mL} \mathrm{~min}^{-1}$.

\section{Solubility test}

The solubility of kraft lignin and the ester derivatives in common solvents was investigated by a brief test. All samples were vacuum dried at $70{ }^{\circ} \mathrm{C}$ for $24 \mathrm{~h}$ before testing. The dried sample (ca. $10 \mathrm{mg}$ ) was weighed into a 1-mL vial, and various solvents were added. Solubility was observed by visual confirmation after standing at room temperature for $24 \mathrm{~h}$.

\section{Thermogravimetric analysis (TGA)}

TGA was performed using a TGA-50 (Shimadzu Co., Kyoto, Japan) equipped with a gas-flow controller (FC60A, Shimadzu Co., Kyoto, Japan) and an analysis system (TA-60, Shimadzu Co., Kyoto, Japan). All samples were vacuum dried at $70{ }^{\circ} \mathrm{C}$ for $24 \mathrm{~h}$ prior to use, and the measurement temperature range was set from 50 to $500{ }^{\circ} \mathrm{C}$ at a heating rate of $10{ }^{\circ} \mathrm{C} \mathrm{min}^{-1}$ in a $\mathrm{N}_{2}$-flow rate of $50 \mathrm{~mL} \mathrm{~min}{ }^{-1}$. A sample of ca. $10 \mathrm{mg}$ was pre-dried at $120{ }^{\circ} \mathrm{C}$ for $2 \mathrm{~h}$. The thermal decomposition temperature $\left(T_{\mathrm{d}}\right)$ was taken as the onset of a $5 \%$ weight loss $\left(T_{\mathrm{d}-5 \%}\right)$.

\section{Dynamic mechanical analysis (DMA)}

The glass transition temperature $\left(T_{\mathrm{g}}\right)$ was investigated using a DMA 8000 instrument (PerkinElmer Japan Co., Ltd., Yokohama, Japan) in a single cantilever mode. The powder samples ( $c a .10 \mathrm{mg}$ ) were enclosed in a folded metal plate named "material pocket". The measurements were carried out under a $\mathrm{N}_{2}$ atmosphere at a heating rate of $2{ }^{\circ} \mathrm{C} \mathrm{min}-1$ from 30 to $300{ }^{\circ} \mathrm{C}$ or to the temperature at which the $T_{\mathrm{g}}$ peak for each sample was clearly observed.

\section{Hot-pressing test}

The powder samples (ca. $0.3 \mathrm{~g})$ were placed in a polytetrafluoroethylene (PTFE) mold $(30 \times 30 \times 0.2 \mathrm{~mm})$, covered between two PTFE sheets, and hot-pressed at a determined temperature under a constant pressure of $5 \mathrm{MPa}$ using a MINI TEST PRESS 10 instrument (Toyo Seiki Seisaku-sho, Ltd., Tokyo, Japan). After hot-pressing, the molded film-like samples were naturally cooled and peeled off from the mold. The thermal processability of 
each sample was determined based on whether the heatmolded sample was a self-standing film with appropriate flexibility.

\section{Results and discussion}

Strategy for development of one-step selective modification of $\mathrm{R}-\mathrm{OH}$ group in kraft lignin

In our previous study, a one-pot two-step chemical modification method using EmimOAc was proposed for the acetylation of the $\mathrm{R}-\mathrm{OH}$ group in kraft lignin with remaining the $\mathrm{Ar}-\mathrm{OH}$ group intact. In this method, IPAc was firstly reacted with both $\mathrm{R}-\mathrm{OH}$ and $\mathrm{Ar}-\mathrm{OH}$ groups for $1 \mathrm{~h}$ at $80^{\circ} \mathrm{C}$. Hereafter, a small amount of water (2 eq./ $[\mathrm{Ar}-\mathrm{OH}])$ was subsequently added as a proton source for the selective deacetylation of the generated Ar-OAc group and heated for more $1 \mathrm{~h}$ at $80^{\circ} \mathrm{C}$ [18]. In this study, for developing a more facile method, our focus was on the fact that the reaction rate of acetylation of the Ar-OH group is much faster than that of the $\mathrm{R}-\mathrm{OH}$ group under the presence of EmimOAc and a limited amount of IPAc [16]. Based on this fact, we assumed that the instantaneously and preferentially generated Ar-OAc group could be selectively deacetylated utilizing the unreacted $\mathrm{R}-\mathrm{OH}$ group as a proton source, and consequently, only the $\mathrm{R}-\mathrm{OH}$ group would be acetylated in a simpler onestep process without the further addition of any other proton sources (e.g., water) as depicted in Scheme 1. Furthermore, the applicability of the reaction system not only to IPAc, but also to various acyl donors is important with respect to the tunability of the material properties of the products. Therefore, a one-step chemical modification method for the esterification of only the $\mathrm{R}-\mathrm{OH}$ group in kraft lignin was first verified using five types of vinyl esters with different alkyl chain lengths as acyl donors.

\section{Appearance, isolated yield, and molecular weight} distribution of products

The products obtained via the one-step chemical modification of kraft lignin using EmimOAc were collected as powder samples (Fig. 1). The original color of kraft lignin

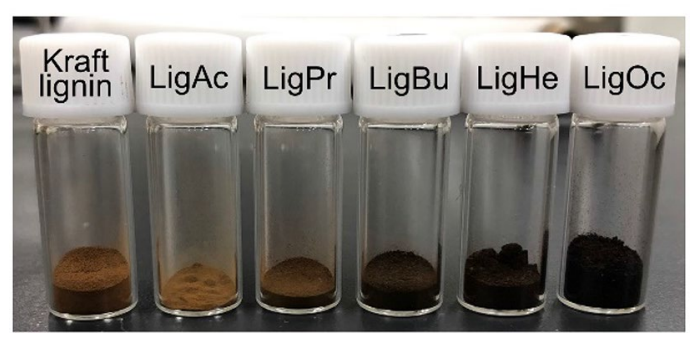

Fig. 1 Appearances of original kraft lignin and the ester derivatives was brown, and the color changed to light brown after acetylation. With increasing alkyl chain lengths of the introduced ester groups, the color of the products further became darker.

Table 2 shows the isolated yields and molecular weight distributions determined by SEC measurements (Fig. 2) of the five types of kraft lignin ester derivatives. All the products were recovered in good isolated yields of $83-92 \%$. Compared to the original kraft lignin, the weight average molecular weight $\left(M_{\mathrm{w}}\right)$ increased from 8.3 to $10 \times 10^{3} \mathrm{~g} \mathrm{~mol}^{-1}$ with an increase in the carbon number of the introduced ester groups. Thus, it was considered that no significant chemical degradation might have occurred during the reaction in the presence of EmimOAc. Furthermore, the polydispersity $(D)$ of kraft lignin was originally 14, while those of the ester derivatives decreased to 9.3-8.9 due to a slight loss of

Table 2 Isolated yield, residual $\mathrm{OH}$ content, and molecular weight distribution of original kraft lignin and the ester derivatives

\begin{tabular}{llll}
\hline Sample & Isolated yield (\%) & $\begin{array}{l}\text { Molecular weight } \\
\text { distribution }\end{array}$ \\
\cline { 3 - 4 } & & $\boldsymbol{M}_{\mathbf{w}}\left(\mathbf{1 0}^{\mathbf{3}} \mathbf{g ~ m o l}^{-\mathbf{1}}\right)$ & $\boldsymbol{\Xi}^{\mathbf{a}}$ \\
\hline Kraft lignin & - & 8.7 & 14 \\
LigAc & 83 & 8.3 & 9.3 \\
LigPr & 86 & 9.5 & 9.2 \\
LigBu & 87 & 9.3 & 9.2 \\
LigHe & 89 & 10 & 9.1 \\
LigOc & 92 & 10 & 8.9 \\
\hline
\end{tabular}

a Polydispersity, $M_{\mathrm{w}} / M_{\mathrm{n}}$

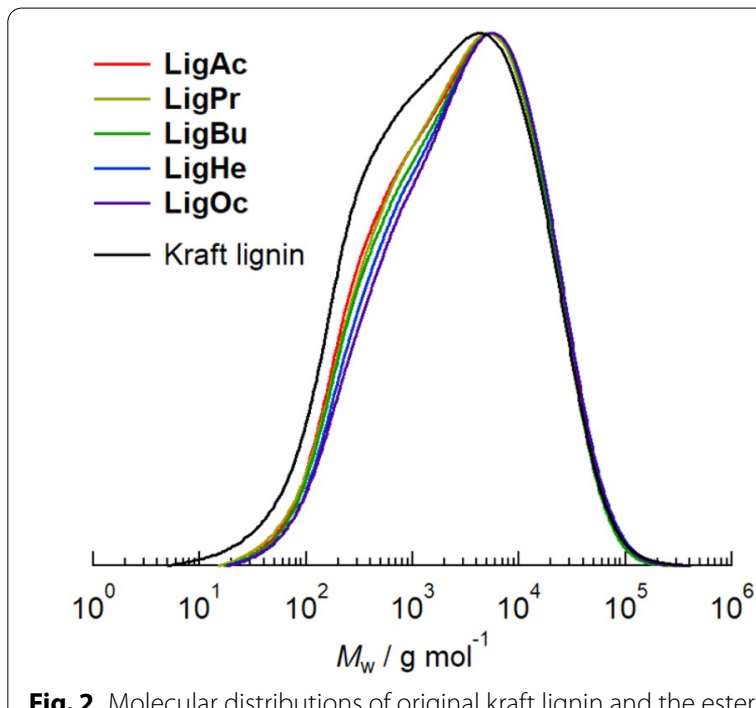

Fig. 2 Molecular distributions of original kraft lignin and the ester derivatives measured using SEC with polystyrene standards 
the low- $M_{\mathrm{w}}$ parts through the reaction and subsequent purification process.

\section{Chemical identification by NMR analyses}

All the products were subjected to ${ }^{1} \mathrm{H}$ and ${ }^{13} \mathrm{C}$-NMR analyses to verify the occurrence of esterification of the $\mathrm{OH}$ groups in kraft lignin. The ${ }^{1} \mathrm{H}$ NMR spectra (Fig. 3a) contained broad peaks at 6.2-7.5 ppm from the aromatic skeleton of lignin and strong peaks at approximately $3.7 \mathrm{ppm}$ from methoxy (OMe) groups. In the spectrum of the original kraft lignin, no clear peak (except for solvent peaks) was observed at 0-3 ppm. On the other hand, for all kraft lignin ester derivatives, new peaks were observed in the same area due to the alkyl protons of the introduced ester groups. Therefore, it was confirmed that kraft lignin was esterified despite the type of vinyl esters.

According to a previous paper, it was reported that the peaks derived from methyl carbons $\left(\mathrm{CH}_{3}-\right)$ in $\mathrm{R}$-OAc and Ar-OAc groups were observed at 1.7-2.1 ppm and 2.2-2.4 ppm, respectively [18]. However, the spectrum of LigAc prepared in this study showed only one peak at the former range, suggesting that the selective modification of $\mathrm{R}-\mathrm{OH}$ group in kraft lignin with Ac group succeeded. For other kraft lignin derivatives with longer acyl groups, almost all the peaks based on the alkyl protons were broadened, making it difficult to determine whether the $\mathrm{R}-\mathrm{OH}$ and/or Ar-OH groups were esterified.

For additional chemical investigation of kraft lignin derivatives, ${ }^{13} \mathrm{C}$-NMR analysis was performed (Fig. $3 \mathrm{~b}$ ). In the ${ }^{13} \mathrm{C}$-NMR spectrum of the original kraft lignin, there were several peaks in the aromatic carbon region from 100 to $150 \mathrm{ppm}$ and strong peaks at approximately $56 \mathrm{ppm}$ corresponding to the OMe groups. Notably, kraft lignin derivatives showed new peaks due to carbonyl carbon $(\mathrm{C}=\mathrm{O})$ of acyl groups at approximately $170 \mathrm{ppm}$, and sharp peaks in the range from 10 to $30 \mathrm{ppm}$ correspond to alkyl carbons of acyl groups. Therefore, consistent with the ${ }^{1} \mathrm{H}$ NMR results, the esterification of kraft lignin using vinyl esters with different alkyl chain lengths was proved.
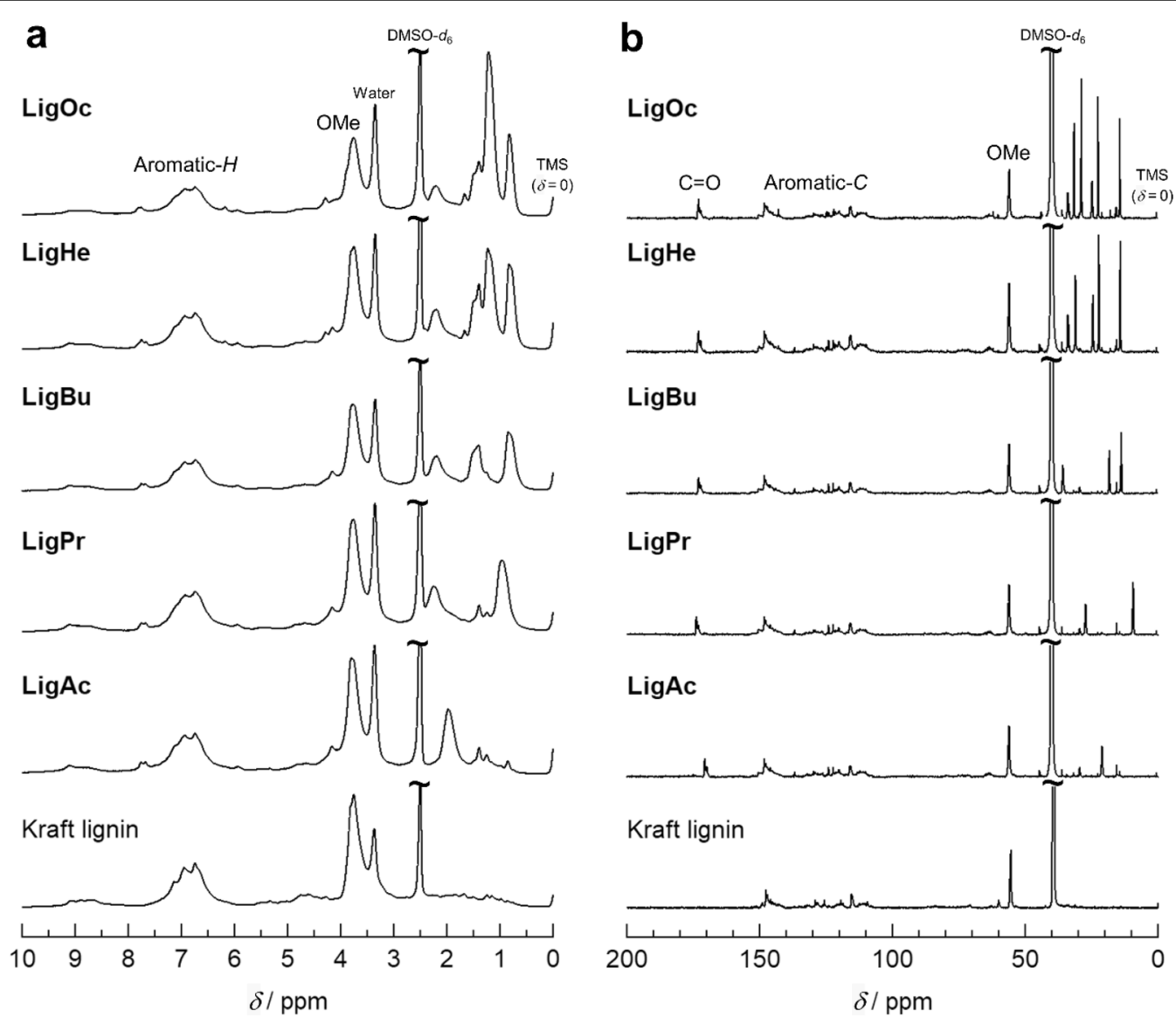

Fig. $3 \mathbf{a}{ }^{1} \mathrm{H}$ - and $\mathbf{b}^{13} \mathrm{C}$-NMR spectra of original kraft lignin and ester derivatives 


\section{Verification of $\mathrm{R}-\mathrm{OH}$ selectivity in transesterification} of kraft lignin using EmimOAc

The above-described ${ }^{1} \mathrm{H}$ and ${ }^{13} \mathrm{C}$-NMR analyses revealed the success of the esterification of kraft lignin using various vinyl esters, but it was difficult to verify the selectivity in the esterification of $\mathrm{R}-\mathrm{OH}$ and Ar-OH groups, owing to the structural complexity of kraft lignin itself. Then, another analytical method was performed to quantify the remaining unreacted $\mathrm{R}-\mathrm{OH}$ and $\mathrm{Ar}-\mathrm{OH}$ groups in the kraft lignin ester derivatives by quantitative ${ }^{31} \mathrm{P}$ NMR analysis after phosphitylation of each sample. In this analytical method, the smaller amount of quantified $\mathrm{OH}$ groups for kraft lignin ester derivatives suggested that the corresponding $\mathrm{OH}$ groups were esterified to a higher degree by the reactions using EmimOAc and vinyl esters.

Figure 4 shows the quantitative ${ }^{31} \mathrm{P}$ NMR spectra of phosphitylated samples. As followed in previous reports $[19,20]$, the peaks of the phosphitylated $\mathrm{R}-\mathrm{OH}$ and Ar-OH groups in lignin are observed in 145.4-150.0 ppm and 137.1-144.0 ppm, respectively. In fact, there were clear peaks in the spectrum of phosphitylated kraft lignin, suggesting that the original kraft lignin contains abundant $\mathrm{R}-\mathrm{OH}$ and Ar-OH groups. Notably, kraft
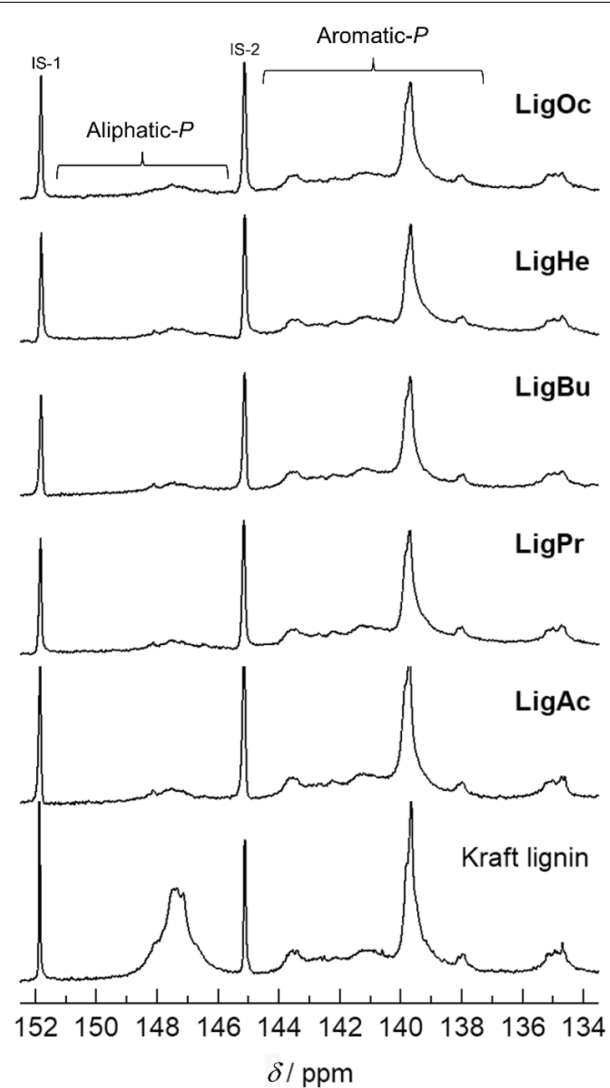

Fig. 4 Quantitative ${ }^{31} \mathrm{P}$ NMR spectra of kraft lignin and the ester derivatives after phosphitylation (IS: internal standard) lignin initially contains a small amount of $\mathrm{COOH}$ group, and this ${ }^{31} \mathrm{P}$ NMR analysis enables the identification of the phosphitylated $\mathrm{COOH}$ group observed in the range of 133.6-136.0 ppm. However, it was clarified by a previous report that the $\mathrm{COOH}$ group was not involved in the transesterification reactions in the presence of EmimOAc [16]. Furthermore, since little change in the $\mathrm{COOH}$ content was observed in this study, it was not included in the discussion here.

As listed in Table 3, although kraft lignin initially contained $2.4 \mathrm{mmol} \mathrm{g}^{-1}$ of $\mathrm{R}-\mathrm{OH}$ group and $3.6 \mathrm{mmol} \mathrm{g}{ }^{-1}$ of Ar-OH group, all the ester derivatives contained only $0.20-0.26 \mathrm{mmol} \mathrm{g}^{-1}$ of $\mathrm{R}-\mathrm{OH}$ group, suggesting that almost all R-OH group was substituted with the corresponding ester groups. In contrast, the residual amount of Ar-OH group was 2.5-3.0 $\mathrm{mmol} \mathrm{g}^{-1}$ : precisely, the $\mathrm{OH}$ content "per gram" slightly decreased, since the molecular weight of the ester derivatives increased with the increase in the carbon number of the introduced ester groups. Based on these results, it was confirmed that the $\mathrm{R}-\mathrm{OH}$ group in kraft lignin was effectively substituted with various ester groups with the remaining the rich Ar-OH group through the one-step chemical modification process using EmimOAc.

Improved solubility of kraft lignin derivatives by selectively introduced long-ester groups

The solubility of polymers in organic solvents with low boiling points is crucial because it enables various molding methods such as solvent casting [21], dry spinning [22], and preparation of nanoparticles in solvents [23]. Moreover, considering the effective utilization of kraft lignin as a polymeric material, it is desirable to increase the originally low molecular weight of kraft lignin [24], which can ensure a certain level of material strength. Therefore, it is essential to obtain "solubility in common solvents" for application to various chemical reactions in

Table $3 \mathrm{OH}$ contents of original kraft lignin and the ester derivatives estimated by a quantitative ${ }^{31} \mathrm{P}$ NMR method

\begin{tabular}{llll}
\hline Sample & \multicolumn{2}{l}{ OH content $\left(\mathbf{m m o l ~}^{-\mathbf{1}}\right)$} \\
\cline { 2 - 4 } & $\mathbf{R - O H}$ & Ar-OH & Total $\mathbf{O H}^{\mathbf{a}}$ \\
\hline Kraft lignin & 2.4 & 3.6 & 6.5 \\
LigAc & 0.26 & 3.0 & 3.6 \\
LigPr & 0.25 & 2.9 & 3.5 \\
LigBu & 0.20 & 2.8 & 3.3 \\
LigHe & 0.23 & 2.7 & 3.2 \\
LigOc & 0.20 & 2.5 & 3.0
\end{tabular}

a Sum up of $\mathrm{R}-\mathrm{OH}, \mathrm{Ar}-\mathrm{OH}$, and $\mathrm{COOH}$ groups 
Table 4 Solubility of original kraft lignin and the ester derivatives in common solvents

\begin{tabular}{|c|c|c|c|c|c|c|}
\hline Solvent & Kraft lignin & LigAc & LigPr & LigBu & LigHe & LigOc \\
\hline Water & - & - & - & - & - & - \\
\hline Methanol & - & - & - & - & - & - \\
\hline DMSO & ++ & ++ & ++ & ++ & ++ & ++ \\
\hline DMF & ++ & ++ & ++ & ++ & ++ & ++ \\
\hline THF & - & - & - & - & ++ & ++ \\
\hline Acetone & - & - & - & - & - & ++ \\
\hline Chloroform & - & - & - & - & + & ++ \\
\hline Hexane & - & - & - & - & - & - \\
\hline
\end{tabular}

++ : soluble $\left(\geq 2 \mathrm{~g} \mathrm{~L}^{-1}\right) ;+$ : partially soluble $\left(<2 \mathrm{~g} \mathrm{~L}^{-1}\right) ;-$ : insoluble

organic solvents, e.g., chemical cross-linking [25-27] and other polymerization reactions $[28,29]$.

Kraft lignin used in this study was soluble in DMSO and DMF, but insoluble in other single solvents listed in Table 4. Generally, the solubility of biopolymers in organic solvents improves by substituting the $\mathrm{OH}$ groups with ester groups. However, it was not clarified to what extent the solubility improves by increasing the alkyl chain lengths of the ester groups introduced onto only the $\mathrm{R}-\mathrm{OH}$ group in lignin. Then, the solubility changes were briefly examined for five types of kraft lignin ester derivatives prepared in this study.

As summarized in Table 4, in the case of short-chain acyl groups, such as acetyl (Ac) and propionyl (Pr) groups, the solubility of the products did not change, plausibly due to the initially small content of the R-OH group in kraft lignin (i.e., $2.4 \mathrm{mmol} \mathrm{g}^{-1}$ ). On the other hand, when long-chain acyl groups of hexanoyl $(\mathrm{He})$ and octanoyl $(\mathrm{Oc})$ were substituted with the $\mathrm{R}-\mathrm{OH}$ group, the solubility in tetrahydrofuran (THF) and chloroform was found to improve. Therefore, it was demonstrated that even a low degree of esterification for only the $\mathrm{R}-\mathrm{OH}$ group successfully enhanced the solubility, depending on the alkyl chain length of the introduced ester groups.

\section{Evaluation of thermal properties of kraft lignin ester derivatives}

Kraft lignin and the ester derivatives were subjected to thermal analyses by thermo-gravimetry (TG) and DMA measurements under a $\mathrm{N}_{2}$ atmosphere. Figure 5a shows the TG curve and the thermal degradation temperature defined as a $5 \%$ weight loss temperature $\left(T_{\mathrm{d}-5 \%}\right)$ for each sample. The $T_{\mathrm{d}-5 \%}$ of the original kraft lignin was $255^{\circ} \mathrm{C}$, and those of the ester derivatives ranged from 241 to $268{ }^{\circ} \mathrm{C}$ regardless of the alkyl chain length of the introduced ester groups. Therefore, it is suggested that the esterification of only the $\mathrm{R}-\mathrm{OH}$ group in kraft lignin has little effect on the thermal stability.
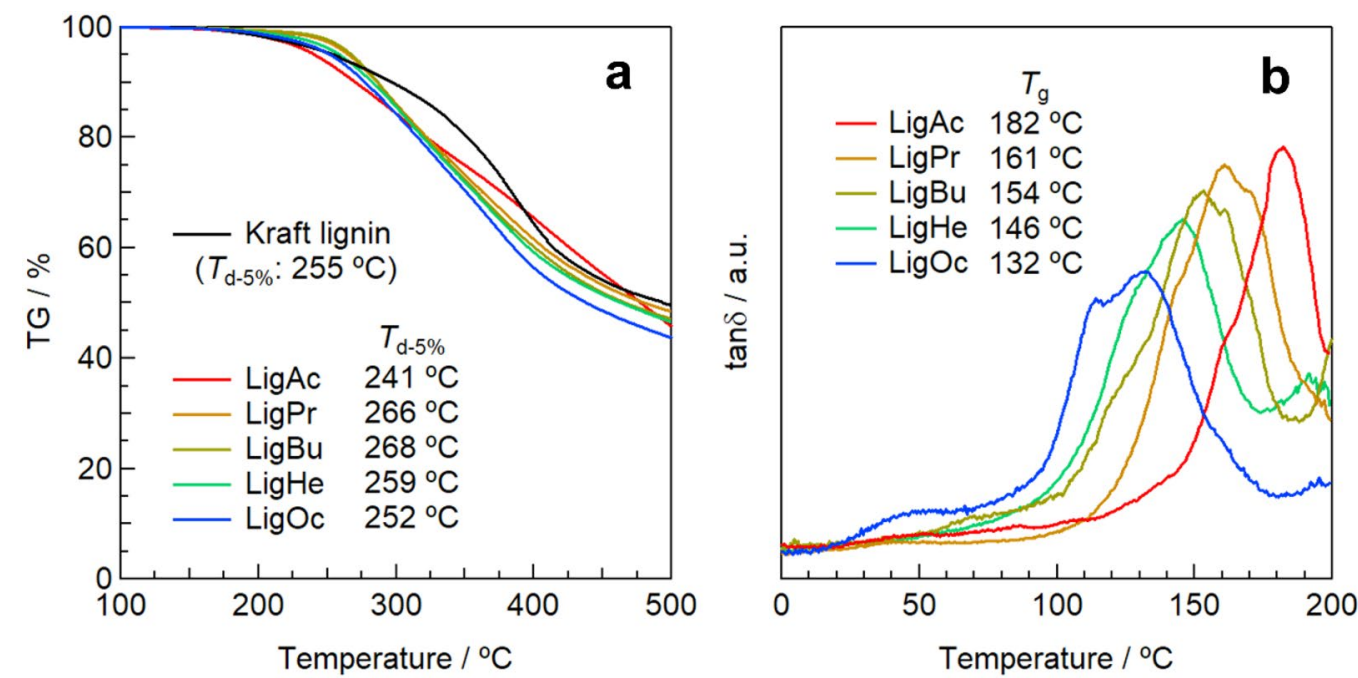

Fig. 5 a TG and $\mathbf{b}$ DMA: $\tan \delta$ as a function of temperature for kraft lignin ester derivatives 
Table 5 Evaluation of heat-moldability in hot-pressing and the resultant films of original kraft lignin and the ester derivatives

\begin{tabular}{lllllll}
\hline & Kraft lignin & LigAc & LigPr & LigBu & LigHe & LigOc \\
\hline $\begin{array}{l}\text { Press temp. }{ }^{\mathrm{a}} \\
\text { Pictures of molded } \\
\text { sample }\end{array}$ & $200{ }^{\circ} \mathrm{C}$ & $180^{\circ} \mathrm{C}$ & $160^{\circ} \mathrm{C}$ & $150{ }^{\circ} \mathrm{C}$ & $145^{\circ} \mathrm{C}$ \\
\end{tabular}

${ }^{\mathrm{a}}$ Determined by $T_{\mathrm{g}}$ and the samples were pressed twice for each $60 \mathrm{~s}$

${ }^{b}$ Considered by the self-standing ability and flexibility of the hot-pressed films

Differential scanning calorimetry (DSC) is very popular for the determination of the glass transition temperature $\left(T_{\mathrm{g}}\right)$ of polymer materials. However, the glass transition of kraft lignin ester derivatives was not clearly observed in the DSC measurements, plausibly due to the heterogeneous structures. Then, the $T_{\mathrm{g}}$ values were determined as the peak top temperatures of $\tan \delta$ measured by DMA for the powder-state samples. Figure $5 \mathrm{~b}$ shows the $\tan \delta$ plots as a function of temperature and the estimated $T_{\mathrm{g}}$ for kraft lignin ester derivatives. The highest $T_{\mathrm{g}}$ of $182{ }^{\circ} \mathrm{C}$ was observed in LigAc substituted with the shortest-chain acyl group, and $T_{\mathrm{g}}$ decreased with increasing the introduced acyl chain length. It should be noted that LigOc substituted with the longest-chain acyl group showed the lowest $T_{\mathrm{g}}$ value of $132{ }^{\circ} \mathrm{C}$, but it was still over $100{ }^{\circ} \mathrm{C}$, implying the potential of kraft lignin ester derivatives to be applied to highly heat-resistant materials.

\section{Evaluation of thermoplasticity as hot-pressing moldability of kraft lignin derivatives}

Thermoplasticity (or heat-meltability) is an important function of polymer materials that enables beneficial forming processes simply by heating, for example, melt spinning [30-32], hot-pressing [33], and injection-molding [34]. Furthermore, it also allows thermal-processing such as polymerization in the molten state in solvent-free systems [35], and melt kneading for blending multiple polymers [36, 37], contributing to the functionalization of polymers and the expansion of their applications. Then, the thermoplasticity was briefly examined by a hotpressing test for kraft lignin ester derivatives.

Table 5 shows pictures of hot-pressed kraft lignin and the ester derivatives. Because kraft lignin does not exhibit thermoplasticity, it remained in a compacted powder form even after hot-pressing at $200{ }^{\circ} \mathrm{C}$. In the case of LigAc and LigPr, it was observed that both powder samples were partially heat melted at the near temperature of $T_{\mathrm{g}}$ and molded as films. However, the resultant films were too brittle to be peeled off from the PTFE mold used during hot-pressing. On the other hand, kraft lignin derivatives with acyl groups longer than butyryl $(\mathrm{Bu})$ showed good thermal moldability through hot-pressing, resulting in uniform and glossy films. These results suggest that kraft lignin successfully acquired sufficient thermoplasticity when the carbon number of the introduced ester groups was larger than 4, even though the esterification was limited to the $\mathrm{R}-\mathrm{OH}$ group. Considered to be utilized as a single material, LigBu, LigHe, and LigOc still have some issues in terms of fragility due to their low molecular weights $\left(M_{\mathrm{w}}, c a .10^{4} \mathrm{~g} \mathrm{~mol}^{-1}\right.$, Table 5). However, the kraft lignin derivatives could be regarded as promising functional precursors that would be applicable to melt blending with other polymers or bulk polymerization such as thermosetting to overcome the disadvantage of molecular weights.

\section{Conclusions}

Through a facile and mild chemical modification method using EmimOAc, ester groups with different alkyl chain lengths were successfully introduced onto the $\mathrm{R}-\mathrm{OH}$ groups in kraft lignin, leaving almost all the Ar- $\mathrm{OH}$ group intact. All the kraft lignin ester derivatives showed high $T_{\mathrm{g}}$ values above $100{ }^{\circ} \mathrm{C}$, implying their potential as precursors for heat-resistant aromatic polymeric materials. Furthermore, it was found that the kraft lignin derivatives in which the $\mathrm{R}-\mathrm{OH}$ group was selectively substituted with long acyl groups, such as $\mathrm{He}$ and Oc groups, showed improved solubility in THF and chloroform and sufficient thermoplasticity, which was evaluated as hotpress moldability at temperatures near $T_{\mathrm{g}}$. Due to their low $M_{\mathrm{w}}$ of $8.3-10 \times 10^{3} \mathrm{~g} \mathrm{~mol}^{-1}$, the kraft lignin ester derivatives might require additional chemical processing (e.g., polymerization and cross-linking) or blending with other polymers for practical use as materials. LigHe and LigOc have good solubility and heat-melting properties, and thus, they can be easily applied to these treatments in solution or melting states. 


\section{Abbreviations}

EmimOAc: 1-Ethyl-3-methylimidazolium acetate; LigAc: Lignin acetate; LigPr: Lignin propionate; LigBu: Lignin butyrate; LigHe: Lignin hexanoate; LigOc: Lignin octanoate.

\section{Acknowledgements}

Not applicable.

\section{Authors' contributions}

SS conducted the experiments, analyzed the obtained data, and wrote the draft of this manuscript. TI completed the final manuscript. Both authors read and approved the final manuscript.

\section{Funding}

This work was carried out as part of a Grant-in-Aid for the Japan Society for the Promotion of Science (JSPS) Research Fellow (No. 19J00642).

\section{Availability of data and materials}

The datasets used and/or analyzed during the current study are available from the corresponding author upon reasonable request.

\section{Declarations}

\section{Competing interests}

The authors declare that they have no competing interests.

Received: 13 July 2021 Accepted: 27 August 2021

Published online: 06 September 2021

\section{References}

1. Chen H (2015) Lignocellulose biorefinery engineering: principles and applications. Woodhead Publishing, Amsterdam, pp 37-86. https://doi. org/10.1016/B978-0-08-100135-6.00003-X

2. Chen J, Yang J, Ma L, Li J, Shahzad N, Kim CK (2020) Structure-antioxidant activity relationship of methoxy, phenolic hydroxyl, and carboxylic acid groups of phenolic acids. Sci Rep 10:2611. https://doi.org/10.1038/ s41598-020-59451-z

3. Catignani GL, Carter ME (1982) Antioxidant properties of lignin. J Food Sci 47:1745-1745. https://doi.org/10.1111/j.1365-2621.1982.tb05029.x

4. Carpentier JF, Kirillov E, Sarazin Y (2009) Metal phenolates as polymerization catalysts. In: PATAl'S chemistry of functional groups. Wiley, New York. https://doi.org/10.1002/9780470682531.pat0606.

5. Ge Y, Li Z (2018) Application of lignin and its derivatives in adsorption of heavy metal ions in water: a review. ACS Sustain Chem Eng 6:7181-7192. https://doi.org/10.1021/acssuschemeng.8b01345

6. Laurichesse S, Avérous L (2014) Chemical modification of lignins: towards biobased polymers. Prog Polym Sci 39:1266-1290. https://doi.org/10. 1016/j.progpolymsci.2013.11.004

7. Liu L-Y, Hua Q, Renneckar S (2019) A simple route to synthesize esterified lignin derivatives. Green Chem 21:3682-3692. https://doi.org/10.1039/ C9GC00844F

8. Koivu KAY, Sadeghifar H, Nousiainen PA, Argyropoulos DS, Sipilä J (2016) Effect of fatty acid esterification on the thermal properties of softwood kraft lignin. ACS Sustain Chem Eng 4:5238-5247. https://doi.org/10.1021/ acssuschemeng.6b01048

9. Hallett JP, Welton T (2011) Room-temperature ionic liquids: solvents for synthesis and catalysis. 2. Chem Rev 111:3508-3576. https://doi.org/10. $1021 / \mathrm{cr} 1003248$

10. Szalaty TJ, Klapiszewski Ł, Stanisz M, Moszyński D, Skrzypczak A, Jesionowski T (2018) Catalyst-free activation of kraft lignin in air using hydrogen sulfate ionic liquids. Int J Biol Macromol 119:431-437. https://doi.org/10. 1016/j.ijbiomac.2018.07.152

11. Szalaty TJ, Klapiszewski $Ł$, Jesionowski T (2020) Recent developments in modification of lignin using ionic liquids for the fabrication of advanced materials_a review. J Mol Liq 301:112417. https://doi.org/10.1016/j.molliq.2019.112417
12. Swatloski RP, Spear SK, Holbrey JD, Rogers RD (2002) Dissolution of celIulose with ionic liquids. J Am Chem Soc 124:4974-4975. https://doi.org/ 10.1021/ja025790m

13. Fu D, Mazza G, Tamaki Y (2010) Lignin extraction from straw by ionic liquids and enzymatic hydrolysis of the cellulosic residues. J Agric Food Chem 58:2915-2922. https://doi.org/10.1021/jf903616y

14. Kakuchi R, Yamaguchi M, Endo T, Shibata Y, Ninomiya K, Ikai T, Maeda K, Takahashi K (2015) Efficient and rapid direct transesterification reactions of cellulose with isopropenyl acetate in ionic liquids. RSC Adv 5:7207172074. https://doi.org/10.1039/C5RA14408F

15. Suzuki S, Shibata Y, Hirose D, Endo T, Ninomiya K, Kakuchi R, Takahashi K (2018) Cellulose triacetate synthesis via one-pot organocatalytic transesterification and delignification of pretreated bagasse. RSC Adv 8:21768-21776. https://doi.org/10.1039/C8RA03859G

16. Suzuki S, Ishikuro A, Hirose D, Ninomiya K, Takahashi K (2018) Dual catalytic activity of an ionic liquid in lignin acetylation and deacetylation. Chem Lett 47:860-863. https://doi.org/10.1246/cl.180350

17. Suzuki S, Ishikuro A, Hamano Y, Hirose D, Wada N, Takahashi K (2020) Understanding and suppression of side reaction during transesterification of phenolic hydroxyl groups of lignin with vinyl ester. Chem Lett 49:900-904. https://doi.org/10.1246/cl.200202

18. Suzuki S, Kurachi S, Wada N, Takahashi K (2021) Selective modification of aliphatic hydroxy groups in lignin using ionic liquid. Catal 11:120. https:// doi.org/10.3390/catal11010120

19. Granata A, Argyropoulos DS (1995) 2-Chloro-4,4,5,5-tetramethyl-1,3,2dioxaphospholane, a reagent for the accurate determination of the uncondensed and condensed phenolic moieties in lignins. J Agric Food Chem 43:1538-1544. https://doi.org/10.1021/jf00054a023

20. Pu Y, Cao S, Ragauskas AJ (2011) Application of quantitative ${ }^{31}$ P NMR in biomass lignin and biofuel precursors characterization. Energy Environ Sci 4:3154-3166. https://doi.org/10.1039/C1EE01201K

21. Siemann $U$ (2005) Solvent cast technology — a versatile tool for thin film production. In: Stribeck N, Smarsly B (eds) Scattering methods and the properties of polymer materials. Springer, Heidelberg, pp 1-14. https:// doi.org/10.1007/b107336

22. Zhang M, Ogale AA (2014) Carbon fibers from dry-spinning of acetylated softwood kraft lignin. Carbon 69:626-629. https://doi.org/10.1016/j. carbon.2013.12.0150

23. Lievonen M, Valle-Delgado JJ, Mattinen M-L, Hult E-L, Lintinen K, Kostiainen MA, Paananen A, Szilvay GR, Setälä H, Österberg M (2016) A simple process for lignin nanoparticle preparation. Green Chem 18:1416-1422. https://doi.org/10.1039/C5GC01436K

24. Saito T, Perkins JH, Vautard F, Meyer HM, Messman JM, Tolnai B, Naskar AK (2014) Methanol fractionation of softwood kraft lignin: impact on the lignin properties. Chemsuschem 7:221-228. https://doi.org/10.1002/cssc. 201300509

25. Asada C, Basnet S, Otsuka M, Sasaki C, Nakamura Y (2015) Epoxy resin synthesis using low molecular weight lignin separated from various lignocellulosic materials. Int J Biol Macromol 74:413-419. https://doi.org/ 10.1016/j.jibiomac.2014.12.039

26. Ciobanu C, Ungureanu M, Ignat L, Ungureanu D, Popa VI (2004) Properties of lignin-polyurethane films prepared by casting method. Ind Crops Prod 20:231-241. https://doi.org/10.1016/j.indcrop.2004.04.024

27. Wang C, Venditti RA (2015) UV cross-linkable lignin thermoplastic graft copolymers. ACS Sustain Chem Eng 3:1839-1845. https://doi.org/10. 1021/acssuschemeng.5b00416

28. Çetin NS, Özmen N (2002) Use of organosolv lignin in phenol-formaldehyde resins for particleboard production: I. Organosolv lignin modified resins. Int J of Adhes Adhes 22:477-480. https://doi.org/10.1016/S01437496(02)00058-1

29. Liu H, Chung H (2016) Self-healing properties of lignin-containing nanocomposite: synthesis of lignin-graft-poly(5-acetylaminopentyl acrylate) via RAFT and Click chemistry. Macromol 49:7246-7256. https://doi.org/ 10.1021/acs.macromol.6b01028

30. Steudle LM, Frank E, Ota A, Hageroth U, Henzler S, Schuler W, Neupert R, Buchmeiser MR (2017) Carbon fibers prepared from melt spun peracylated softwood lignin: an integrated approach. Macromol Mater Eng 302:1600441. https://doi.org/10.1002/mame.201600441

31. Nordström Y, Norberg I, Sjöholm E, Drougge R (2013) A new softening agent for melt spinning of softwood kraft lignin. J Appl Polym Sci 129:1274-1279. https://doi.org/10.1002/app.38795 
32. Awal A, Sain M (2013) Characterization of soda hardwood lignin and the formation of lignin fibers by melt spinning. J Appl Polym Sci 129:27652771. https://doi.org/10.1002/app.38911

33. Zhang Y, Wu J-Q, Li H, Yuan T-Q, Wang Y-Y, Sun R-C (2017) Heat treatment of industrial alkaline lignin and its potential application as an adhesive for green wood-lignin composites. ACS Sustain Chem Eng 5:7269-7277. https://doi.org/10.1021/acssuschemeng.7b01485

34. Sahoo S, Misra M, Mohanty AK (2013) Effect of compatibilizer and fillers on the properties of injection molded lignin-based hybrid green composites. J Appl Polym Sci 127:4110-4121. https://doi.org/10.1002/app. 37667

35. Cateto CA, Barreiro MF, Rodrigues AE, Belgacem MN (2011) Kinetic study of the formation of lignin-based polyurethanes in bulk. React Funct Polym 71:863-869. https://doi.org/10.1016/j.reactfunctpolym.2011.05.007
36. Sakai H, Kuroda K, Muroyama S, Tsukegi T, Kakuchi R, Takada K, Hata A, Kojima R, Ogoshi T, Omichi M, Ninomiya K, Takahashi K (2018) Alkylated alkali lignin for compatibilizing agents of carbon fiber-reinforced plastics with polypropylene. Polym J 50:281-284. https://doi.org/10.1038/ s41428-017-0009-3

37. Sakai H, Kuroda K, Tsukegi T, Ogoshi T, Ninomiya K, Takahashi K (2018) Butylated lignin as a compatibilizing agent for polypropylene-based carbon fiber-reinforced plastics. Polym J 50:997-1002. https://doi.org/10. 1038/s41428-018-0088-9

\section{Publisher's Note}

Springer Nature remains neutral with regard to jurisdictional claims in published maps and institutional affiliations.

\section{Submit your manuscript to a SpringerOpen ${ }^{\circ}$ journal and benefit from:}

- Convenient online submission

- Rigorous peer review

- Open access: articles freely available online

- High visibility within the field

Retaining the copyright to your article

Submit your next manuscript at $\gg$ springeropen.com 